\title{
Radiotherapy after Mastectomy for Screen-Detected Ductal Carcinoma in Situ
}

Karen Clements, West Midlands Cancer Screening QA Reference Centre, Public Health England, 1st Floor, 5 St Philip's Place, Birmingham B3 2PW, UK

David Dodwell

Institute of Oncology, Level 4 - Bexley Wing, St James Hospital, Leeds, LS9 7TF, UK

Gill Lawrence

West Midlands Cancer Screening QA Reference Centre, Public Health England, 1st Floor, 5 St Philip's Place, Birmingham B3 2PW, UK

Graham Ball

Van Geest Cancer Research Centre, School of Science and Technology, Nottingham Trent University, Clifton Lane, Nottingham, NG11 8NS

Adele Francis

Ward West 2, Queen Elizabeth Hospital, Edgbaston, Birmingham, B15 2TH, UK

Sarah Pinder

Research Oncology, Division of Cancer Studies, King's College London, 3rd Floor, Bermondsey Wing, Guy's Hospital, Great Maze Pond, London SE1 9RT, UK

Elinor Sawyer

Research Oncology, Division of Cancer Studies, King's College London, 3rd Floor, Bermondsey Wing, Guy's Hospital, Great Maze Pond, London SE1 9RT, UK

Matthew Wallis

Cambridge Breast Unit, Box 97 - NIHR Cambridge Biomedical Research Centre Addenbrooke's Hospital, Hills Road, Cambridge, CB2 2QQ

Alastair M. Thompson

Department of Breast Surgical Oncology, MD Anderson Cancer Center, 1515-1400 Pressler StreetHolcombe Boulevard, Houston 7703008

on behalf of the Sloane Project Steering Group. 


\section{Abstract}

Background. A role for radiotherapy after mastectomy for ductal carcinoma in situ (DCIS) is unclear. Using a prospective audit of DCIS detected through the NHS Breast Screening Programme we sought to determine a rationale for the use of postmastectomy radiotherapy for DCIS.

Methods. Over a nine year period, from 9,972 patients with screen-detected DCIS and complete surgical, pathology, radiotherapy and follow up data, 2,944 women underwent mastectomy for DCIS of whom 33 (1.12\%) received radiotherapy.

Results. Use of post mastectomy radiotherapy was significantly associated with a close $(<1 \mathrm{~mm})$ pathology margin, particularly $\left(\chi^{2}(1) 95.81 ; p<0.00001\right)$, DCIS size $\left(\chi^{2}(3)\right.$ 16.96; $p<0.001)$ and the presence of microinvasion $\left(\chi^{2}(1) 3.92 ; p<0.05\right)$. At median follow up 61 months, no woman who received radiotherapy had an ipsilateral further event, and only $1 / 33$ women (3.0\%) had a contralateral event. Of the women known not to have had radiotherapy post mastectomy, 45/2,894 (1.6\%) had an ipsilateral further event and 83 (2.9\%) had a contralateral event.

Conclusion: For DCIS treated by mastectomy, a close $(<1 \mathrm{~mm})$ margin, large tumour size and microinvasion, may merit radiotherapy to reduce ipsilateral recurrence. 


\section{Introduction}

The prognosis for screen-detected ductal carcinoma in situ (DCIS) is excellent and within the UK NHS Breast Screening Programme (NHSBSP) relative breast cancerspecific mortality is no different to an unaffected population (1). Mastectomy is still commonly performed for DCIS and is in the great majority of cases curative. Local recurrence after mastectomy is rare (2).

In the context of early invasive breast cancer, rather than DCIS, radiotherapy is almost always recommended after breast conserving surgery (BCS) and removes around $70 \%$ of the risk of recurrence (3). Radiotherapy following mastectomy for invasive disease is also recommended if recurrence risk is high. The Early Breast Cancer Trialists' Collaborative Group (EBCTCG) overview reports that patients with positive lymph nodes have a $23 \%$ local recurrence risk without radiotherapy and a $6 \%$ risk if radiotherapy is given (risk reduction $74 \%$ ) (3). Following BCS for DCIS, radiotherapy reduces the risk of (invasive and in situ) recurrence by $54 \%$ (4), but is utilised infrequently after mastectomy $(5,6,7)$.

Although there are retrospective data $(5,6,7)$, no prospective studies have examined the effects of post-mastectomy radiotherapy (PMRT) in DCIS. In order to understand the possible reasons why PMRT may be recommended for DCIS after mastectomy, the prospectively collected NHS Breast Screening Programme audit data were interrogated to compare demographic and histopathological variables with outcomes in women receiving radiotherapy and those who did not post mastectomy. 


\section{Methods}

The prospective audit of NHS breast screen-detected non-invasive breast carcinoma and atypical hyperplasia (the Sloane Project, named after eminent pathologist John Sloane) accrued patients from 2003-2012. Eighty nine percent of NHS breast screening units geographically spread across the UK_participated in the audit, and data were captured on $40 \%$ of all women with screen detected non-invasive neoplasia. Data capture at source was through manually completed radiology, surgery, pathology and radiotherapy forms, collated onto a single data base. The Sloane Project is administered by the West Midlands Cancer Screening Quality Assurance Reference Centre, part of Public Health England. A Steering Committee comprises surgeons, pathologists, radiologists, oncologists and a patient advocate. Further details of the Sloane Project are available through the website (www.sloaneproject.org.uk).

The prospectively collected Sloane Project database was examined retrospectively to identify women treated for DCIS who had undergone mastectomy. Data were extracted including the age of diagnosis, histological features, use of and recorded indication for PMRT. Further events were identified by matching the cases by NHS number and date of birth to information provided by Sloane contacts in NHS breast screening units and to routinely collected datasets, which included Cancer Waiting Times, Hospital Episode Statistics, the English National Radiotherapy Dataset, the English Cancer Analysis System/National Cancer Registration Service and datasets held by the Information Services Division Scotland. The census date for further events and deaths was 31 December 2012; giving a median follow up time of 61 months. Women who died of breast cancer but who had no further events recorded were deemed to have had distant metastases on the date they died. If there was no evidence of women having a contralateral breast cancer diagnosis, distant events were deemed to be 'ipsilateral distant events'.

\section{Statistics}

Pearson's chi-squared test was used to test for a significant difference between those receiving radiotherapy or not receiving radiotherapy following mastectomy according to age at diagnosis, tumour size, final margin size, cytonuclear grade of the DCIS, presence of microinvasion and presence of comedo necrosis. A chi-squared probability of less than or equal to 0.05 was interpreted as the cut-off point at which there was a significant difference and thus the point at which the null hypothesis could be rejected. 


\section{Results}

12,838 women with a diagnosis of screen-detected DCIS in the 9-year period between $1 / 4 / 2003$ and $31 / 3 / 2012$ were prospectively entered into the Sloane Project database; 9,972 (78\%) women had complete and informative data in relation to surgical operation, radiotherapy utilisation, DCIS size and/or margin status and followup (Figure 1). Of these 9,972 surgically treated women, 2,944 (30\%) underwent mastectomy as their final surgical procedure ${ }_{L}$ and $33(1.12 \%)$ of these women were confirmed to have received post-operative radiotherapy (Figure 1). The 33 women who received radiotherapy were treated in 16 different NHS breast screening units.

The use of PMRT was related to margin status and this was statistically significant when the margin was $<1 \mathrm{~mm}\left(x^{2}(1)=95.81 \mathrm{p}<0.00001\right)$. Of the $925(31 \%)$ women with data on margin status, $16 \%$ (16/99) with final margin status $<1 \mathrm{~mm}$ received radiotherapy and $4 \%(3 / 78)$ with margin status $1-<2 \mathrm{~mm}$ received radiotherapy. There was no association between size of margin and tumour recurrence in the women treated by mastectomy for DCIS. There was also a significant association with increasing tumour size $\left(\chi^{2}(3)=16.96, p<0.001\right.$; for tumours with known size), with women who had DCIS $>50 \mathrm{~mm}$ being more likely to receive radiotherapy $\left(\chi^{2}(1)=8.60\right.$, $\mathrm{p}<0.01)$. There also appeared to be a borderline significant association with the presence of microinvasion $\left(\chi^{2}(1)=3.92, p<0.05\right.$; for tumours with known microinvasive status). Although the use of radiotherapy was lower in women with low cytonuclear grade tumours and higher in those with tumours with comedo necrosis present, these differences were not statistically significant (Table 1). There was no significant association of radiotherapy use with patient age.

No woman who received radiotherapy had an ipsilateral further event (defined as ipsilateral chest wall, ipsilateral axilla or distant metastatic disease in the absence of a contralateral breast cancer) at median follow up 61 months, and only 1 woman had a contralateral breast cancer (Table 2). However, $26(0.9 \%)$ of the women who were known not to have had radiotherapy had an ipsilateral locoregional event (23 had an ipsilateral breast event and 3 had an ipsilateral nodal event) and 19 (0.7\%) had a distant (metastatic) event. A further 83 women (2.9\%) who were known not to have had radiotherapy had a contralateral breast cancer. The majority (24/26; 92\%) of the women with locoregional ipsilateral events had invasive recurrencecancer (21 had an invasive ipsilateral breast event and 3 had an invasive ipsilateral nodal event). № significant difference was seen between the frequencies of recurrencefurther events betweenin women treated with radiotherapy RT treated-and those known not to have beenpatietns not treated with radiotherapyRT untreated forin non recurrence no further events, contralateral recurrenceevents, ipsilateral recurrenceevents andor metastasis $\left(\left(x^{2}(9)=0.209, p=0.99\right)\right.$. Of the women who had locoregional events, $19 / 26(73 \%)$ had a high cytonuclear grade primary, $21 / 26$ (81\%) had comedo necrosis 
in their primary tumour and $8 / 26(31 \%)$ had a primary DCIS over $50 \mathrm{~mm}$ in diameter. Of the 19 women with distant events, 15/19 (79\%) had a high cytonuclear grade primary, 15/19 (79\%) had comedo necrosis in their primary tumour and 8/19 (42\%) had a primary tumour with a size greater than $50 \mathrm{~mm}$. The majority $(32 / 45)$ of ipsilateral further events in the no radiotherapy group occurred in women where margin status was not recorded. Of the recurrencesfurther events (131), 12 showed micro--invasion (9.16\%).

\section{Discussion}

There have been no randomised trials (nor are there likely to be) addressing the use of radiotherapy after mastectomy for DCIS. This large, prospective, audit has confirmed that few women (1.12\%) with screen-detected DCIS receive PMRT. Within this context, the strongest association was with margin status recorded for the use of radiotherapy (5), presumably due to the risk of local recurrence in the view of the surgeon/radiotherapist caring for the patient. The current audit has the advantage of large numbers of patients with screen-detected DCIS and median 61 months follow up. However, the partially complete data, low use of radiotherapy and nonrandomised data reflect the imperfections of clinical audit data.

Local recurrence after mastectomy for DCIS has been reported, but is rare, and may be followed by metastatic disease (8), but is rare. While recurrence may occur after breast conservation for DCIS, over 15 years or more from the original treatment $(11)_{2}$ local recurrence with longer term follow up after mastectomy may be correspondingly higher than generally reported. However, given that most case series avoid radiotherapy in all, or almost all ${ }_{2}$ cases of DCIS treated with mastectomy (5), chest wall recurrence after post mastectomy radiotherapy for DCIS has only rarely been reported (6). A meta-analysis of published studies reported a $1.4 \%$ recurrence rate fof further DCIS or mastectomy) after mastectomy for DCIS (2). Others have shown a $1 \%$ local recurrence at around 6 years of follow up, unchanged over 2 decades $(8,9,10)$ similar to the recurrence rate reported here at 5 years.

There are limited data on the identification of patients who are at increased risk of recurrence of carcinoma after mastectomy for DCIS. Rashtian et al studied the consequences of close or positive margins after mastectomy for DCIS (12). From an original cohort of 574 patients, 80 patients who did not receive radiotherapy were identified with margins of $<10 \mathrm{~mm}, 6(7.5 \%)$ of these patients developed local recurrence at a median follow-up of 61 months. Of these 6 patients, 5 originally had DCIS with margins of excision of $2 \mathrm{~mm}$ or less, 5 were high grade disease, 5 had comedo necrosis, and all were under 60 years of age. $5 / 31$ (16\%) cases with resection margins less than or equal to $2 \mathrm{~mm}$ developed local recurrence, comparable with the data presented here. All of the recurrences were invasive, and 3 patients developed 
metastatic disease. Pathological review of the original mastectomy blocks did not identify any invasive disease at the time of diagnosis. In contrast, it has been reported (10) that margin status was only a significant factor for recurrence for patients treated with BCS and not after mastectomy, leading others to suggest that the risk of chest wall recurrence was too low to recommend adjuvant radiotherapy (13).

The majority of screen-detected DCIS studied here was high grade, in keeping with current UK quality assured pathology (?refneeded). There may be a disparity between different national practices, or proportions of patients entering a clinical trial - for example only $37 \%$ patients had high grade DCIS in the NSABP B-17 trial. The potential over-treatment of DCIS, use of patient and healthcare resources and the complications of radiotherapy $(14,15)$ suggests the need to identify biomarkers for the minority of women who are likely tomight benefit from PMRT.

This prospective audit of screen detected DCIS demonstrates the infrequent use of PMRT for DCIS in routine clinical practice. Positive margin status and high grade disease appear to be used as potential indications for PMRT. Further follow up within this and other large datasets of patients treated for DCIS should clarify possible indications forPMRT. 


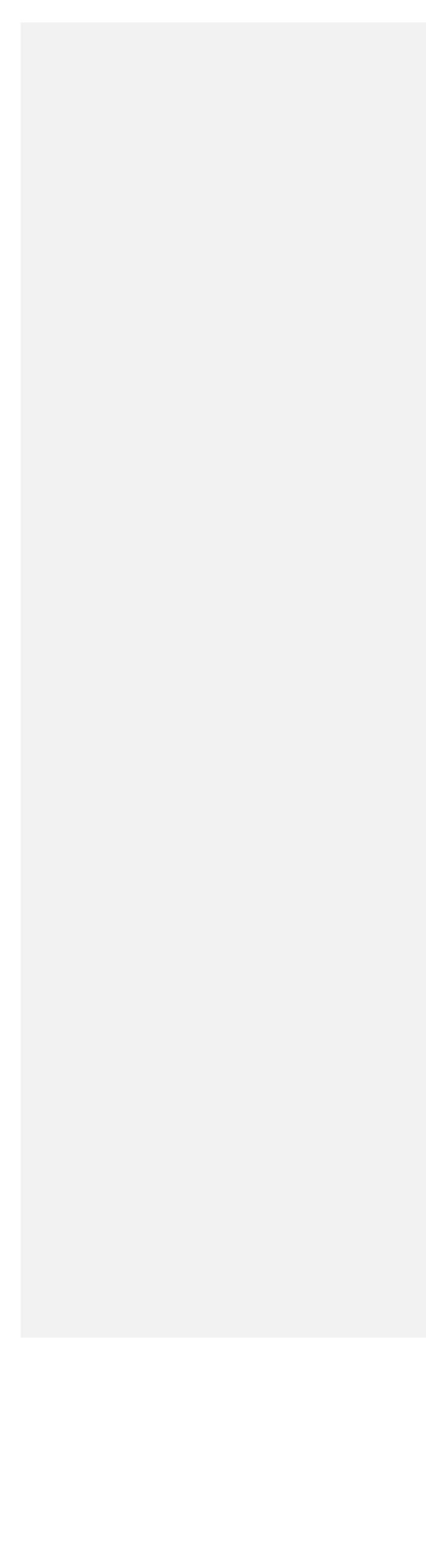




\section{References}

1) http://www.cancerscreening.nhs.uk/breastscreen/publications/baso2011-2012.pdf

2) Boyages J, Delaney G, Taylor R. Predictors of local recurrence after treatment of ductal carcinoma in situ: a meta-analysis. Cancer 1999; 85:616-628.

3) Clarke M1, Collins R, Darby S, Davies C, Elphinstone P, Evans E, Godwin J, Gray R, Hicks C, James S, Mackinnon E, McGale P, McHugh T, Peto R, Taylor C, Wang Y; Early Breast Cancer Trialists' Collaborative Group (EBCTCG). Effects of radiotherapy and of differences in the extent of surgery for early breast cancer on local recurrence and 15-year survival: an overview of the randomised trials. Lancet. 2005 Dec 17; 366(9503):2087-106.

4) Early Breast Cancer Trialists' Collaborative Group (EBCTCG), Correa C, McGale P, Taylor C, Wang Y, Clarke M, Davies C, Peto R, Bijker N, Solin L, Darby S. Overview of the randomized trials of radiotherapy in ductal carcinoma in situ of the breast. J Natl Cancer Inst Monogr. 2010; 41:162-77. doi: 10.1093/jncimonographs/lgq039.

5) Fitzsullivan E, Lari SA, Smith B, Caudle AS, Krishnamurthy S, Lucci A, Mittendorf EA, Babiera GV, Black DM, Wagner JL, Bedrosian I, Woodward W, Gainer SM, Hwang R, Meric-Bernstam $\mathrm{F}$, Hunt KK, Kuerer HM. Incidence and consequence of close margins in patients with ductal carcinoma-in situ treated with mastectomy: is further therapy warranted? Ann Surg Oncol. 2013; 20(13):4103-12.

6) Childs SK, Chen YH, Duggan MM, Golshan M, Pochebit S, Punglia RS, Wong JS, Bellon JR. Impact of margin status on local recurrence after mastectomy for ductal carcinoma in situ. Int J Radiat Oncol Biol Phys. 2013 Mar 15; 85(4):948-52.

7) Vargas $C^{1}$, Kestin L, Go N, Krauss D, Chen P, Goldstein N, Martinez A, Vicini FA. Factors associated with local recurrence and cause-specific survival in patients with ductal carcinoma in situ of the breast treated with breast-conserving therapy or mastectomy. Int J Radiat Oncol Biol Phys. 2005; 63(5):1514-21.

8) Silverstein MJ, Barth A, Poller DN, et al. Ten-year results comparing mastectomy to excision and radiation therapy for ductal carcinoma in situ of the breast. Eur J Cancer 1995; 31A:1425-1427.

9) Meijnen P, Oldensburg HS, Peterse JL, Bartelink JL, Rutgers EJ. Clinical outcome after selective treatment of patients diagnosed with ductal carcinoma in situ of the breast. Ann Surg Oncol 2008; 15:235-243.

10) Shouten van der Velden, AP, van Vugt R, van Dijck JA, Leer JW, Wobbes T. Local recurrences after different treatment strategies for ductal carcinoma in situ of the breast: a populationbased study in the East Netherlands. Int J Radiat Oncol Biol Phys 2007; 69:703-710.

11) Wallis M G, Clements K, Kearins O, Ball G, Macartney J and Lawrence G. The effect of DCIS grade on rate, type and time to recurrence after 15 years of follow-up of screen-detected DCIS. British Journal of Cancer 2012; 106:1618-1625 
12) Rashtian A, Iganej S, Amy Liu IL, Natarajan S. Close or positive margins after mastectomy for DCIS: pattern of relapse and potential indications for radiotherapy. Int J Radiat Oncol Biol Phys 2008; 72:1016-1020

13) Chan LW, Rabban J, Hwang ES, et al. Is radiation indicated in patients with ductal carcinoma in situ and close or positive mastectomy margins? Int J Radiat Oncol Biol Phys 2011; 80:2530.

14) Early Breast Cancer Trialists' Collaborative Group. Favourable and unfavourable effects of radiotherapy on long-term survival for early breast cancer: an overview of the randomised trials. Lancet 2000; 355:1757-1770.

15) Darby SC, McGale P, Taylor CW, Peto R. Long-term mortality from heart disease and lung cancer after radiotherapy for early breast cancer: prospective cohort study of about 300,000 women in US SEER cancer registries. Lancet Oncol 2005; 6:557-565. 
Figure 1: Case consort diagram

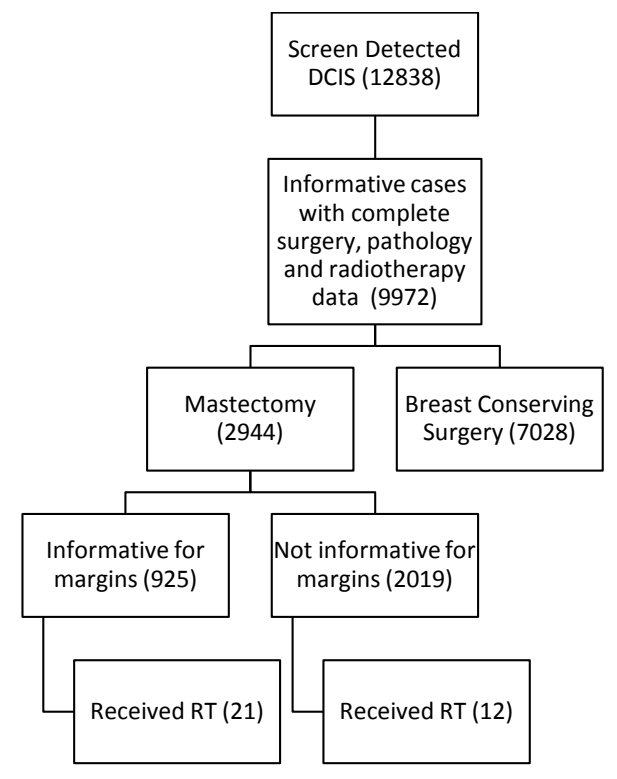


Table 1: Use of post mastectomy radiotherapy (\%)

\begin{tabular}{|c|c|c|c|c|}
\hline \multirow[b]{2}{*}{ Parameter } & \multicolumn{4}{|c|}{ Radiotherapy (RT) } \\
\hline & $\begin{array}{c}\text { No. }(\%) \text { RT } \\
\text { not given }\end{array}$ & $\begin{array}{l}\text { No. (\%) } \\
\text { RT given } \\
\text { Given }\end{array}$ & $\begin{array}{l}\text { No. (\%) RT } \\
\text { unknown }\end{array}$ & Total no. (\%) \\
\hline \multicolumn{5}{|c|}{ Age at diagnosis (years) } \\
\hline$<50$ & $93(100.00)$ & $0(0.00)$ & $0(0.00)$ & $93(3.16)$ \\
\hline $50-64$ & $2054(98.32)$ & $26(1.24)$ & $9(0.43)$ & $2089(70.96)$ \\
\hline $65-70$ & $622(98.11)$ & $5(0.79)$ & $7(1.10)$ & $634(21.54)$ \\
\hline 71-73 & $64(96.97)$ & $2(3.03)$ & $0(0.00)$ & $66(2.24)$ \\
\hline $74+$ & 61 (98.39) & $0(0.00)$ & $1(1.61)$ & $62(2.11)$ \\
\hline Total & $2894(98.30)$ & $33(1.12)$ & $17(0.58)$ & $2944(100.00)$ \\
\hline \multicolumn{5}{|c|}{ Tumour size $(\mathrm{mm})$} \\
\hline $0-20$ & 707 (98.88) & $4(0.56)$ & $4(0.56)$ & 715 (24.29) \\
\hline$>20-50$ & $1406(98.46)$ & $14(0.91)$ & $9(0.63)$ & $1428(48.51)$ \\
\hline$>50-100$ & $669(97.66)$ & $12(1.75)$ & $4(0.58)$ & $685(23.27)$ \\
\hline$>100$ & 70 (94.59) & $4(5.41)$ & $0(0.00)$ & $74(2.51)$ \\
\hline Unknown & $42(100.00)$ & $0(0.00)$ & $0(0.00)$ & $42(1.43)$ \\
\hline Total & $2894(98.30)$ & $33(1.12)$ & $17(0.58)$ & $2944(100.00)$ \\
\hline \multicolumn{5}{|c|}{ Final margin distance $(\mathrm{mm})$} \\
\hline 0 & $29(72.50)$ & $11(27.50)$ & $0(0.00)$ & $40(1.36)$ \\
\hline$>0-<1$ & $54(91.53)$ & $5(8.47)$ & $0(0.00)$ & $59(2.00)$ \\
\hline $1-<2$ & $74(94.87)$ & $3(3.85)$ & $1(1.28)$ & $78(2.65)$ \\
\hline $2-<5$ & $138(98.57)$ & $1(0.71)$ & $1(0.71)$ & $140(4.76)$ \\
\hline $5=10$ & $196(98.99)$ & $0(0.00)$ & $2(1.01)$ & $198(6.73)$ \\
\hline$>10$ & $408(99.51)$ & $1(0.24)$ & $1(0.24)$ & 410 (13.93) \\
\hline Unknown & $1995(98.81)$ & $12(0.59)$ & $12(0.59)$ & $2019(68.58)$ \\
\hline Total & $2894(98.30)$ & $33(1.12)$ & $17(0.58)$ & $2944(100.00)$ \\
\hline \multicolumn{5}{|c|}{ Cytonuclear grade of DCIS } \\
\hline Low & $138(100.00)$ & $0(0.00)$ & $0(0.00)$ & $138(4.69)$ \\
\hline Intermediate & $572(98.11)$ & $4(0.69)$ & $7(1.20)$ & $583(19.80)$ \\
\hline High & $2184(98.25)$ & $29(1.30)$ & $10(0.45)$ & $2223(75.51)$ \\
\hline Total & $2894(98.30)$ & $33(1.12)$ & $17(0.58)$ & $2944(100.00)$ \\
\hline \multicolumn{5}{|c|}{ Microinvasion present } \\
\hline Yes & 251 (96.91) & $6(2.32)$ & $2(0.77)$ & $259(8.80)$ \\
\hline No & 2617 (98.49) & $26(0.98)$ & $14(0.53)$ & $2657(90.25)$ \\
\hline Unknown & $26(92.86)$ & $1(3.57)$ & $1(3.57)$ & $28(0.95)$ \\
\hline Total & $2894(98.30)$ & 33 (1.12) & $17(0.58)$ & $2944(100.00)$ \\
\hline \multicolumn{5}{|c|}{ Comedo necrosis present } \\
\hline Yes & 2085 (98.49) & $24(1.13)$ & $8(0.38)$ & $2117(71.91)$ \\
\hline No & $647(98.48)$ & $6(0.91)$ & $4(0.61)$ & $657(22.32)$ \\
\hline Unknown & 162 (95.29) & $3(1.76)$ & $5(2.94)$ & $170(5.77)$ \\
\hline TOTAL & 2894 (98.30) & $33(1.12)$ & $17(0.58)$ & $2944(100.00)$ \\
\hline
\end{tabular}


Table 2 Variation in ipsilateral (ipsilateral chest wall, ipsilateral axilla or metastatic disease in the

absence of a contralateral cancer) and contralateral further events with radiotherapy and margin status

for women treated with mastectomy (further events before 31/12/12)

\begin{tabular}{|c|c|c|c|c|c|c|c|c|c|c|c|c|c|c|c|}
\hline \multirow[b]{2}{*}{$\begin{array}{c}\text { Final } \\
\text { margin } \\
(\mathrm{mm})\end{array}$} & \multicolumn{5}{|c|}{ Radiotherapy not given } & \multicolumn{4}{|c|}{ Radiotherapy given } & \multicolumn{5}{|c|}{ Radiotherapy Unknown } & \multirow[b]{2}{*}{$\begin{array}{c}\text { No. All } \\
\text { Mx } \\
\text { cases }\end{array}$} \\
\hline & $\begin{array}{l}\text { No. (\%) } \\
\text { Ipsi- } \\
\text { lateral } \\
\text { loco- } \\
\text { regional }\end{array}$ & $\begin{array}{l}\text { No. (\%) } \\
\text { All ipsi- } \\
\text { lateral }\end{array}$ & $\begin{array}{c}\text { No. (\%) All } \\
\text { contra- } \\
\text { lateral }\end{array}$ & $\begin{array}{c}\text { No. No } \\
\text { further } \\
\text { event } \\
\text { before } \\
31 / 12 / 12\end{array}$ & $\begin{array}{c}\text { Total } \\
\text { No. } \\
\text { RT } \\
\text { not } \\
\text { given }\end{array}$ & $\begin{array}{l}\text { No. (\%) } \\
\text { All ipsi- } \\
\text { lateral }\end{array}$ & $\begin{array}{c}\text { No. (\%) } \\
\text { All } \\
\text { contra- } \\
\text { lateral }\end{array}$ & $\begin{array}{c}\text { No. No } \\
\text { further } \\
\text { event } \\
\text { before } \\
31 / 12 / 12\end{array}$ & $\begin{array}{c}\text { Total } \\
\text { No. } \\
\text { RT } \\
\text { given }\end{array}$ & $\begin{array}{c}\text { No. (\%) } \\
\text { Ipsi- } \\
\text { lateral } \\
\text { loco- } \\
\text { regional }\end{array}$ & $\begin{array}{l}\text { No. (\%) } \\
\text { All ipsi- } \\
\text { lateral }\end{array}$ & $\begin{array}{c}\text { No. (\%) } \\
\text { All } \\
\text { contra- } \\
\text { lateral }\end{array}$ & $\begin{array}{c}\text { No. No } \\
\text { further } \\
\text { event } \\
\text { before } \\
31 / 12 / 12\end{array}$ & $\begin{array}{c}\text { Total No. } \\
\text { Unknown } \\
\text { RT }\end{array}$ & \\
\hline 0 & $1(3.45 t$ & $2(6.90)$ & $1(3.45)$ & 26 & 29 & $0(0.00)$ & $1(9.09)$ & 10 & 11 & $0(0.00)$ & $0(0.00)$ & $0(0.00)$ & 0 & 0 & 40 \\
\hline$>0-<1$ & $0(0.00)$ & $1(1.85)$ & $0(0.00)$ & 53 & 54 & $0(0.00)$ & $0(0.00)$ & 5 & 5 & $0(0.00)$ & $0(0.00)$ & $0(0.00)$ & 0 & 0 & 59 \\
\hline $1-<2$ & $0(0.00)$ & $0(0.00)$ & $2(2.70)$ & 72 & 74 & $0(0.00)$ & $0(0.00)$ & 3 & 3 & $0(0.00)$ & $0(0.00)$ & $0(0.00)$ & 1 & 1 & 78 \\
\hline $2-<5$ & $2(1.45)$ & $4(2.90)$ & $3(2.17)$ & 131 & 138 & $0(0.00)$ & $0(0.00)$ & 1 & 1 & $0(0.00)$ & $0(0.00)$ & $1(100)$ & 0 & 1 & 140 \\
\hline $5-10$ & $1(0.51)$ & $2(1.02)$ & $4(2.04)$ & 190 & 196 & $0(0.00)$ & $0(0.00)$ & 0 & 0 & $0(0.00)$ & $0(0.00)$ & $0(0.00)$ & 2 & 2 & 198 \\
\hline$>10$ & $2(0.49)$ & $4(0.98)$ & $14(3.42)$ & 390 & 408 & $0(0.00)$ & $0(0.00)$ & 1 & 1 & $0(0.00)$ & $0(0.00)$ & $0(0.00)$ & 1 & 1 & 410 \\
\hline Unknown & $20(1.02)$ & $32(1.60)$ & $59(2.96)$ & 1904 & 1995 & $0(0.00)$ & $0(0.00)$ & 12 & 12 & $1(8.33)$ & $1(8.33)$ & $0(0.00)$ & 11 & 12 & 2019 \\
\hline Total & $26(0.90)$ & $45(1.55)$ & $83(2.87)$ & 2766 & 2894 & $0(0.00)$ & $1(3.03)$ & 32 & 33 & $1(5.88)$ & $1(5.88)$ & $1(5.88)$ & 15 & 17 & 2944 \\
\hline
\end{tabular}

